\title{
Synthesis and Characterization of $\mathrm{BaBiO}_{3}$ Perovskite through Chemical Route
}

\author{
Fanta Legesse , Sreenu K*, Senbeto Kena and Kebede Legesse \\ Department of Physics, College of Computational and Natural Sciences, Wollega University, P.O Box: 395, \\ Nekemte, Ethiopia

\begin{tabular}{|c|c|}
\hline Abstract & Article Information \\
\hline \multirow{3}{*}{$\begin{array}{l}\mathrm{BaBiO}_{3} \text { (perovskite) polycrystalline semiconducting material was synthesized by sol-gel } \\
\text { chemical method. Structure of the sample was characterized by X-Ray Diffraction } \\
\text { (XRD). Grain, Grain boundary topography and chemical composition of the sample } \\
\text { studied by using Scanning Electron Microscope (SEM) and Energy Dispersive X- Ray } \\
\text { Spectrometry (EDS). Fourier transform-infrared spectroscopy (FT-IR) was used for the } \\
\text { study of band structure. The result of XRD characterization was indicated as the } \\
\mathrm{BaBiO}_{3} \text { is monoclinic perovskite and crystalline size is } 85 \mathrm{~nm} \text {. SEM image of the } \\
\mathrm{BaBiO}_{3} \text { showed the grain size of } 85 \mathrm{~nm} \text {. The FT-IR spectroscopy study showed that, } \\
\text { the } \mathrm{BaBiO}_{3} \text { has absorbent peak at } 1420 \mathrm{~cm}^{-1} \text {. }\end{array}$} & \begin{tabular}{l}
\multicolumn{2}{l}{ Article History: } \\
Received $: 21-01-2015$ \\
Revised $: 22-03-2015$ \\
Accepted $: 25-03-2015$
\end{tabular} \\
\hline & $\begin{array}{l}\text { Keywords: } \\
\text { Bismuth Titanate } \\
\text { Perovskite } \\
\text { Monoclinic }\end{array}$ \\
\hline & $\begin{array}{l}\text { *Corresponding Author: } \\
\text { Sreenu Kasam } \\
\text { E-mail: cnukasam@gmail.com }\end{array}$ \\
\hline
\end{tabular}

\section{INTRODUCTION}

The $\mathrm{BaBiO}_{3}$ which belong to the crystallographic family called perovskite (Robert M. Hazen, 1998) is known by its charge distortion i.e. $\mathrm{Bi}$ occupies two distinctive sites, having bond length of $\mathrm{Bi}(1)-\mathrm{O}=2.28 \AA \AA$ and $\mathrm{Bi}(2)-\mathrm{O}=$ $2.12 \AA$ (Sven Larsson, 1996). This differences in distance are the reason for the charge disproportionation occurred in the way that $2 \mathrm{Bi}^{+4}=\mathrm{Bi}^{+3}+\mathrm{Bi}^{+5}$, which results in the insulating property in this compound. The cubic $\mathrm{BaBiO}_{3}$ has an odd number of electrons in each unit cell and it is expected to be a metal, from simple electronic band model because the mean valence of $\mathrm{Bi}$ is $4+$, i.e. valence band mainly composed of $\mathrm{Bi} 6 \mathrm{~s}$ orbital should be halffilled, however $\mathrm{BaBiO}_{3}$ shows semiconducting temperature dependence of electrical conductivity, experimentally (Takuya Hashimoto et al., 2008). But, A or $B$ sire doping suppresses the charge density waves to produce the metallic superconducting phases (Shen et al., 1990) which means that semiconducting property should be changed to semi-metallic or metallic by modification of crystal structure to higher symmetry with single Bi site. One of the probable methods is a partial cation substitution to $\mathrm{BaBiO}_{3}$. It has already been reported that $\mathrm{K}$ substitution of $\mathrm{Ba}$ site or $\mathrm{Pb}$ one of $\mathrm{Bi}$ site causes variation of crystal structure to higher symmetry accompanied by semiconductor-metal transition and that superconducting transition is also observed in $\mathrm{Ba}_{0.6} \mathrm{~K}_{0.4} \mathrm{BiO}_{3}$ and $\mathrm{BaPb}_{1 \times} \mathrm{Bi}_{\times} \mathrm{O}_{3}\left(x^{1 / 4} \quad 0.1-0.35\right)$. It can be concluded that chemical state of $\mathrm{Bi}$ was affected by the cation substitution resulting in variation of crystal structure and electrical conduction property (Takuya Hashimoto et al., 2008). The high temperature super conductivity of the Kdoped in the $\mathrm{Ba}$ site and $\mathrm{Pb}$-doped in the $\mathrm{Bi}$ site made this compound very interesting. The mechanism of the hightemperature superconductivity in $\mathrm{Ba}_{\mathrm{x}} \mathrm{K}_{\mathrm{x}} \mathrm{BiO}_{3}$ is still the open question. This material has a rather high critical temperature $T_{c} \approx 30 \mathrm{~K}(\mathrm{x} \approx 0.4)$ for a system without a layered structure in contrast to $\mathrm{CuO}$ planes in cuprates (Dm. M. Korotin, 2013). More than two decades ago it was found that the superconducting transition temperature $T_{\mathrm{c}}$ of $\mathrm{Ba}_{1-\mathrm{x}} \mathrm{K}_{\mathrm{x}} \mathrm{BiO}_{3}$ is close to $30 \mathrm{~K}$ (for $x=0.4$ ), one of the highest among materials without copper or iron. Unlike copper- and iron based superconductors, $\mathrm{Ba}_{1-x} \mathrm{~K}_{x} \mathrm{BiO}_{3}$ is nonmagnetic and its electrons are likely paired by a more conventional electron-phonon coupling mechanism (Timur Bazhirov et al., 2013). Super conductivity in $\mathrm{Ba}(\mathrm{Pb}, \mathrm{Bi}) \mathrm{O}_{3}$ over acomposition range $0.1<\mathrm{x}<0.3$ was discovered in 1975 by Sleight et al with a maximum $T_{C}$ of $13.5 \mathrm{~K}$. Superconductivity in the $(\mathrm{Ba}, \mathrm{K}) \mathrm{BiO}_{3}$ was discovered in 1988 by Matthesis and his colleagues (Grumann et al 1994).

The crystal structure of $\mathrm{BaBiO}_{3}$ was determined to be monoclinic at room temperature in 1976, 1979 by Cox and Sleight using powder neutron diffraction. This result was supported by neutron diffraction studies and $\mathrm{x}$-ray absorption studies (Akhtar et al., 1993). In this compound, two different $\mathrm{BiO}_{6}$ octahedral are connected alternatively by edge-sharing mode along the crystallographic directions. One octahedron is tilted from the vertical c-axis and the next one is tilted in opposite direction to construct a zigzag structure with the angle of $159.9^{\circ}$ (Dongwoon Jung et al., 1999).

\section{MATERIALS AND METHODS}

The sol-gel method widely used to produce nano crystalline $\mathrm{BaBiO}_{3}$ powders and films. This process involved dissolving the metal-containing compounds in the solvent, hydrolyzing to polymeric condensation, drying the resulting solution into various gels, and, finally, annealing 


\section{Fanta Legesse et al.,}

the gels at high temperature to form $\mathrm{BaBiO}_{3}$ nano crystals (Sreenu et al., 2014) In this process, the choice of starting materials, concentration, $\mathrm{pH}$ value, and heat treatment schedule had a strong influence on the properties of the $\mathrm{BaBiO}_{3}$ nanoparticles. However, the different rates in the hydrolysis and condensation of $\mathrm{Ba}$ and $\mathrm{Bi}$ precursors often led to chemical component segregation in the obtained gels. The stachometric amounts of barium nitrate $\left(\mathrm{Ba}\left(\mathrm{NO}_{3}\right)\right)_{2}$ (Merck $\left.99 \%\right)$ is taken in aqueous solution and Bismuth nitrate $\left(\mathrm{Bi}\left(\mathrm{NO}_{3}\right)_{3} 5 \mathrm{H}_{2} \mathrm{O}\right)$ is added to the solution. The mixture is slowly heated on a hot plate and citric acid is added. The $\mathrm{pH}$ value is adjusted to desired value by adding ammonium hydroxide solution. Ethylene glycol is added to the mixture and heated till precursor is obtained. The precursor is burned at $600^{\circ} \mathrm{C}$ for 5 hours. Finally calcinated at $800{ }^{0} \mathrm{C}$ in furnace of oxygen atmosphere then the resultant powder was crushed and pressed into circular pellets of $10 \mathrm{~mm}$ diameter and $\sim 1 \mathrm{~mm}$ thickness. The possible chemical reactions are as follows:

$$
\mathrm{Ba}\left(\mathrm{NO}_{3}\right)_{2}+\mathrm{Bi}\left(\mathrm{NO}_{3}\right)_{3} 5 \mathrm{H}_{2} \mathrm{O} \rightarrow \mathrm{BaBiO}_{3}+5 \mathrm{NO}_{2} \uparrow+5 \mathrm{H}_{2} \mathrm{O} \uparrow
$$

The crystalline structure of the prepared samples was analyzed with X-ray diffraction. The microstructure of the samples was investigated by using scanning electron microscope (Hitachi N3400 Japan). The FTIR patterns were acquired by using BRUKER OPTICS, Germany Model TENSOR 27 FTIR spectrometer from $4000 \mathrm{~cm}^{-1}$. $400 \mathrm{~cm}^{-1}$, using $\mathrm{KBr}$ pellet as a reference material.

\section{RESULTS AND DISCUSSION}

In nature everything has got its own uniqueness so to be identified from one another they have to be characterized. Characterization is a wonderful method for identifying one sample from other because same time we
Sci. Technol. Arts Res. J., Jan-March 2015, 4(1): 80-83

are not able differentiate samples by their texture, color, odor and the like. Therefore, a $\mathrm{BaBiO}_{3}$ sample was characterized by $x$-ray diffraction, Scanning Electron Microscope, Energy Dispersive x-ray Spectroscopy and Fourier Transform Infrared Spectroscopy.

\section{Structural Studies}

Many techniques are used to characterize the solids. Among them, the most important is x-ray diffraction studies, which gives information about the phase formation of the compound, lattice parameters, theoretical density. X-ray patterns were taken on the pre-sintered and final sintered samples. By comparing the powder diffraction of the samples with standard patterns given in JCPDS (Joint Committee on Powder Diffraction standards, USA), lattice parameters were evaluated using the powd software, which is based on the least square minimization procedure. The $\mathrm{x}$-ray powder diffraction may also be used to measure the average crystal size from the peak broadening using the Scherer formula.

As shown in figure 1 the XRD detector reads both angle $(2 \theta)$ of $x$-ray diffraction and the intensity of diffracted $X$-ray which resulted in a two dimensional pattern called characteristic pattern of $\mathrm{BaBiO}_{3}$ ("finger print of $\mathrm{BaBiO}_{3}$ "). The materials were examined by $\mathrm{x}$-ray powder diffraction for phase purity and hence it showed single phase of $\mathrm{BaBiO}_{3}$

From powd program it was found that each respective parameters to be $a=6.33 \AA, b=6.12 \AA, c=8.62 \AA$ and with $\beta=90.171$. This confirms that $\mathrm{BaBiO}_{3}$ has monoclinic structure at room temperature. The calculated crystalline size using the Scherer formula was $85 \mathrm{~nm}$ as well. And its XRD density was $6.13 \mathrm{gcm}^{-3}$.

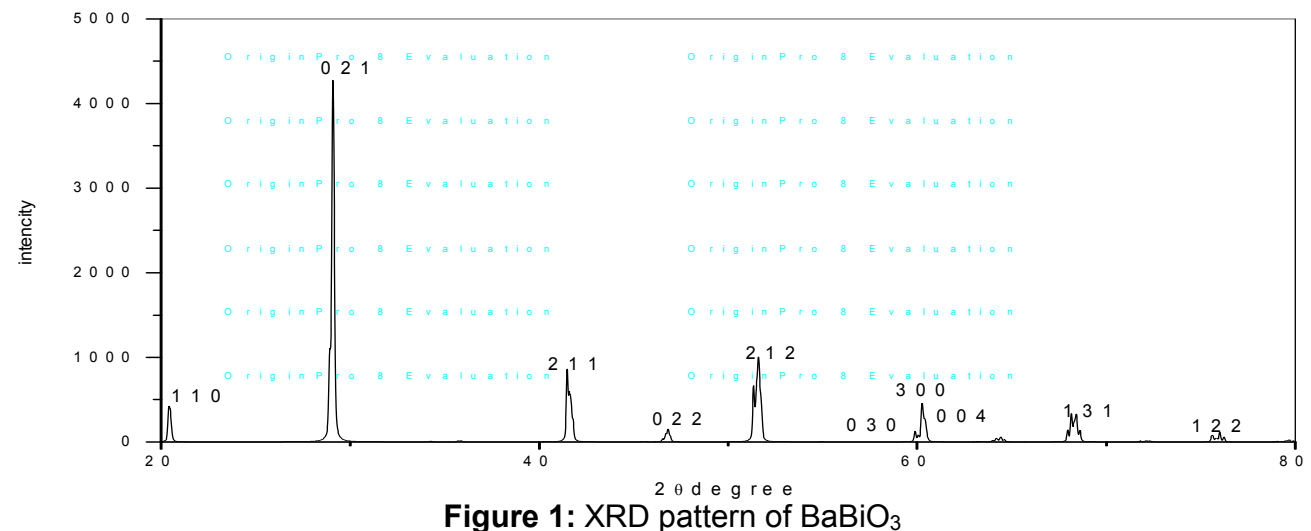

\section{Micro Structural Properties of $\mathrm{BaBiO}_{3}$ Ceramics}

The close observation at the micrograph of $\mathrm{BaBiO}_{3}$ figure 2 taken from SEM showed large grain size at the boundary this is expected to be due to existence $\mathrm{Bi}$ ions in the sample (Sreenu et al., 2014) with same porosity and scratches. The grain site was around $4 \mu \mathrm{m}$ in uniform as calculated using line interept method.

\section{Compositional Distribution Study}

An interaction of an electron beam with a sample target produces a variety of emissions, including $\mathrm{x}$-rays. An energy-dispersive (EDS) detector is used to separate the characteristic $X$-rays of different elements into an energy spectrum, and EDS system software is used to analyze the energy spectrum in order to determine the abundance of specific elements. EDS can be used to find the chemical composition of materials down to a spot size of a few microns, and to create element composition maps over a much broader raster area.

In figure 3 each energy peak of the EDS pattern corresponds to elements in the sample i.e. $\mathrm{Ba}, \mathrm{Bi}$ and $\mathrm{Au}$. The showing up of gold in the pattern is because the sample was coated with gold before its characterization of SEM.

The EDS does not only tell us the elemental composition of the sample but also shows the relative abundance of each chemical element in the sample (Table 1).

Table 1: elemental weight of $\mathrm{BaBiO}_{3}$

\begin{tabular}{ccccc}
\hline Elements & $\mathbf{O}$ & $\mathbf{B a}$ & $\mathbf{B i}$ & $\mathbf{A u}$ \\
\hline Weight & 11.81 & 21.07 & 49.78 & 12.33
\end{tabular}




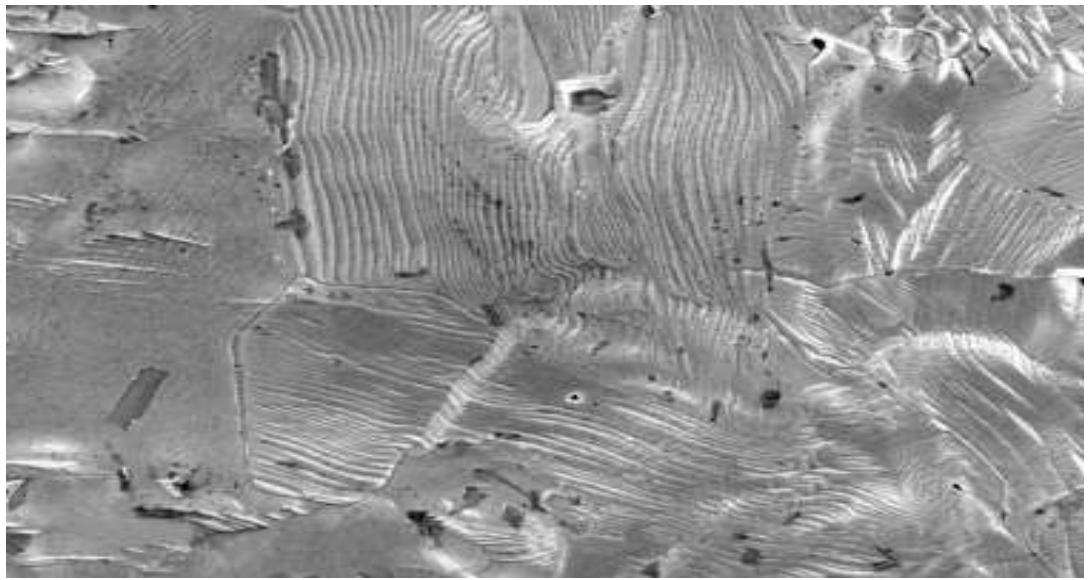

Figure 2: the micrograph of $\mathrm{BaBiO}_{3}$ taken by SEM

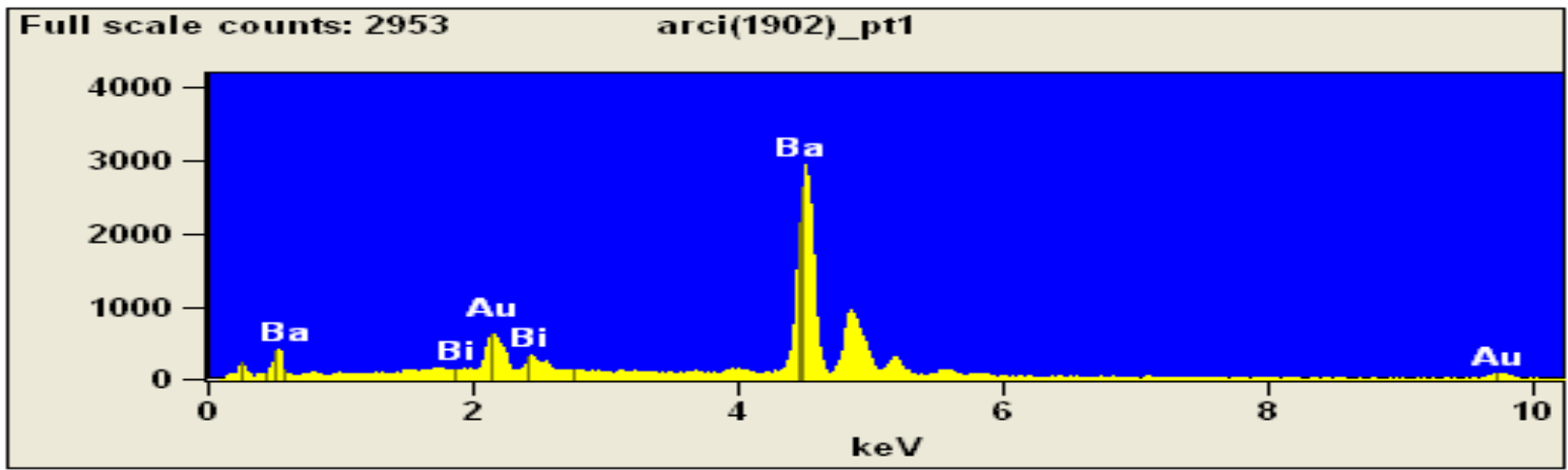

Figure 3: EDS pattern of $\mathrm{BaBiO}_{3}$

\section{Fourier Transform Infrared Spectroscopy (FTIR)}

A molecule absorbs radiation at certain frequency, which cause a quantum change in its energy. The IR radiation has correct frequency to cause a quantum jump in the vibration energy of the molecule. The vibrations of a molecule absorb the radiation of IR radiation, which the oscillations cause a change in the dipole moment. The frequency at which the absorption takes place is equal to frequency of oscillations of the dipole and falls in the region.IR spectra of all the samples are recorded in the range $4000-400 \mathrm{~cm}^{-1}$ (Figure 4). From this FTIR pattern it is seen that pure $\mathrm{BaBiO}_{3}$ shows as absorption at $1420 \mathrm{~cm}^{-}$ ${ }^{1}$ which are considered to be a characteristic feature of the sample and are attributed to $\mathrm{Ba}-\mathrm{O}$ band bending vibrations. Even though some ions are different, the absorption peak in the vicinity of $540 \mathrm{~cm}^{-1}$ is assigned to the vibration of $\mathrm{O}-\mathrm{M}(\mathrm{M}=\mathrm{ion}$ at $\mathrm{B}-\mathrm{site})$ bond i.e. $\mathrm{O}-\mathrm{Bi}$ (Table 2).

Table 2: Infrared band positions $\left(\mathrm{cm}^{-1}\right)$ of $\mathrm{BaBiO}_{3}$

\begin{tabular}{cc}
\hline Band position & Wave No(cm $\left.{ }^{-1}\right)$ \\
\hline Ba-O & 1420 \\
\hline \multirow{2}{*}{$\mathrm{Bi}-\mathrm{O}$} & 702 \\
& 520 \\
\hline
\end{tabular}

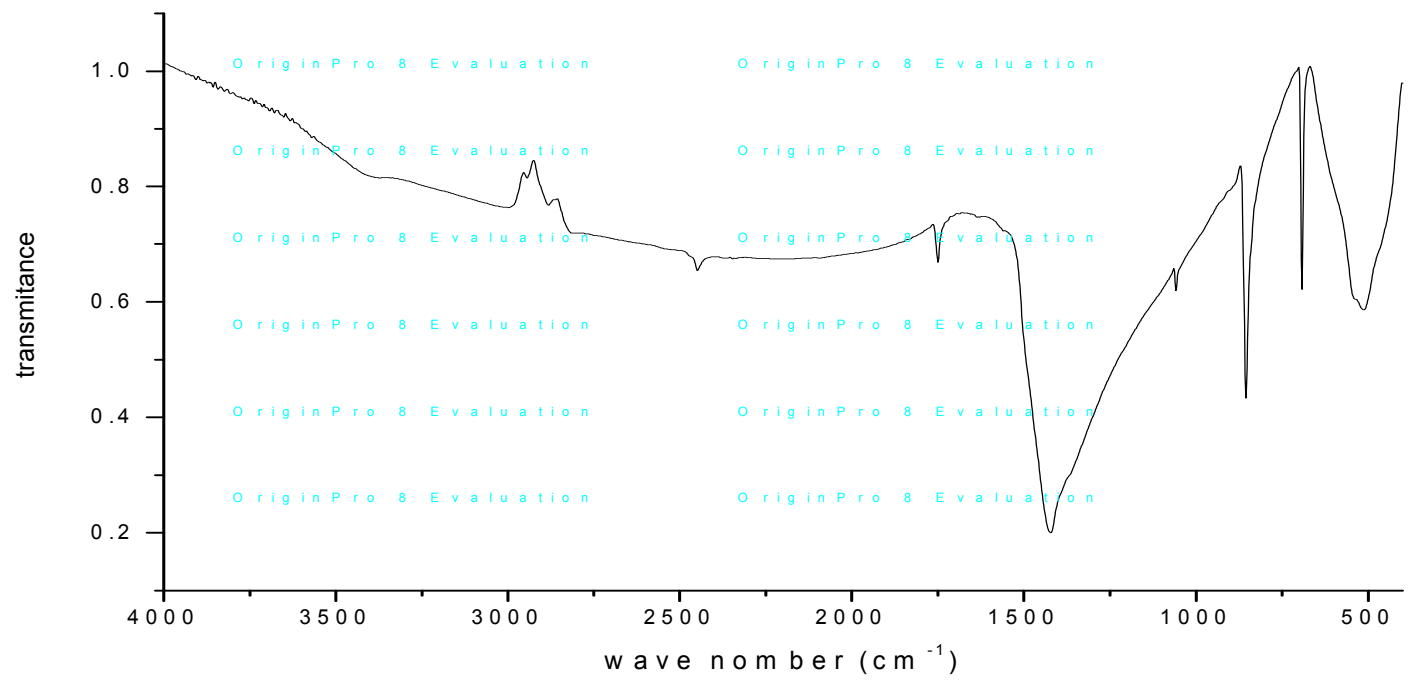

Figure 4: Infrared spectra of barium bismuthate 


\section{Fanta Legesse et al.,}

\section{CONCLUSIONS}

$\mathrm{BaBiO}_{3}$ polycrystalline material is synthesized by solgel method having the crystallite size of $85 \mathrm{~nm}$ and the $x$ rd characterization with lattice parameters $a=6.33 \AA$, $b=$ $6.12 \AA$ and $\mathrm{c}=8.62 \AA$ and unit volume is $334 \mathrm{~cm}^{3}$ indicates that $\mathrm{BaBiO}_{3}$ is monoclinic perovskite at room temperature with percentage of density $94\left(\mathrm{gm} / \mathrm{cm}^{3}\right)$. SEM results reveal that the grain size is large because of the $\mathrm{Bi}$-ion. The EDS analyze of sintered pellet of $\mathrm{BaBiO}_{3}$ reviled that the sample was pure. From the detailed FTIR spectra analysis, it was observed that the pronounced peak at $1420 \mathrm{~cm}^{-1}$, where a metallic bond is observed, considered being a characteristic feature of $\mathrm{BaBiO}_{3}$.

\section{Conflict of Interest}

Conflict of interest none declared.

\section{Acknowledgements}

Authors are grateful to the Advanced Research Centre Immarat (ARCI), Hyderabad, India, Indian Institute of Chemical Technology (IICT), Hyderabad for providing experimental data and Department of Chemistry, Wollega University.

\section{REFERENCES}

Banwell, C.N. and Mc Cash, E.M. (1994). Fundamentals of Molecular Spectroscopy, $4^{\text {th }}$ edition Tata McGraw Hill, New Delhi.

Dm. M. Korotin. (2013). Correlation effects and phonon modes softening with doping in $\mathrm{Ba}_{1-\mathrm{x}} \mathrm{K}_{\mathrm{x}} \mathrm{BiO}_{3}$. Institute of Metal Physics 1-6.

Dongwoon Jung and Eun-Kuk Choi. (1999). Differences of Structural and Electronic Properties in $\mathrm{Ba}_{1-\mathrm{x}} \mathrm{K}_{\mathrm{x}} \mathrm{BiO}_{3}(x=0$, 0.04 , and 0.4). Bulletin of Korean Chemistry Society 20(9): 1045

Goldstein, J.I. and Newbury, D.E. (1981). Scanning Electron Microscopy and X-ray Microanalysis. Plenum Press, New York.
Sci. Technol. Arts Res. J., Jan-March 2015, 4(1): 80-83

Grumann, M.G., Balakrishnan, G., Tomy, C.V., McK, D. (1994) Paul Superconducting properties of $\mathrm{Ba}(\mathrm{Pb}, \mathrm{Bi}) \mathrm{O}_{3}$ single crystal and melt-processed $(\mathrm{Ba}, \mathrm{K}) \mathrm{BiO}_{3}$. Physica $\mathrm{C}$ 226: 288-292.

Klug, H.P. and Alexander, A.E. (1956). Elements of X-ray Diffraction Procedures. John Wiley Inc, New York.

Liu, W.L., Xia, H.R., Han, H. and Wang, X.Q. (2004). Structural and electrical characteristics of $\mathrm{Bi}_{3.5} \mathrm{Sm}_{0.5} \mathrm{Ti}_{3} \mathrm{O}_{12}$

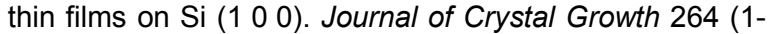
3): 351-356.

McMillan, P. (1984). Structural studies of silicate glasses and melts -applications and limitations of Raman spectroscopy. American Mineralogist 69: 622-644.

Patterson, A.L. (1939). The Scherrer Formula for X-Ray Particle Size Determination. Physical Review 56: 978992.

Reimer, L. and Tolkamp, C. (1980). Measuring the backscattering coefficient and secondary electron yield inside a SEM. Scanning 3: 35-41.

Shen, Z.X., Lindberg, P.A.P., Wells, B.O., Dessau, D.S., Borg, A., Lindau, I., Spice, W.E. (1990). Electronic Structure Of Monoclinic $\mathrm{BaBiO}_{3}$. Stanford Electronics Laboratories, American Institute of Physics. USA.

Sreenu, K., Bhargavi, T. and Kebede Legesse Kabeta (2014). Characterization and Phase Transitions of $\mathrm{Bi}$ Doped $\mathrm{BaTiO}_{3}$ Ceramics Prepared through Chemical Route. Science, Technology and Arts Research Journal 3(1): 3943.

Sven Larson. (1996). Four-site four -electron for Bi (IIII)$\mathrm{Bi}(\mathrm{V})$ mixed valence complex. Inorganica Chemica Acta 250: 189-193.

Takuya Hashimoto., Makoto Yamaguchi., Yoshitaka Sakurai., Eri Oikawa. (2008). Effect of oxygen nonstoichiometry on electrical conduction property of $\mathrm{BaBiO}_{3} \delta$. Journal of Physics and Chemistry of Solids 69: 284-288.

Timur Bazhirov., Sinisa Coh., Steven G. Louie., and Marvin L. Cohen. (2013). Importance of oxygen octahedra tilts for the electron-phonon coupling in K-doped $\mathrm{BaBiO}_{3}$. Physical Review B 88: 224509. 